\title{
THE PROTECTIVE EFFECT OF THE CARTHMUS TINCTORIUS LEAVES EXTRACTON METHOTREXATE-INDUCED PULMONARY FIBROSIS IN RATS
}

\author{
HANAA SALMAN KHADHEM*, MAHDI MTHUWAINI**, WAJDY J. MAJID ${ }^{* * *}$ \\ ${ }^{*}$ College of Science, University of Basra, ${ }^{* *}$ College of Medical and Healthy Techniqes, Southern Technical University, ${ }^{* * *}$ College of Medicine, \\ Thi qar Universiy-Iraq \\ Email: hanaa.salman831973@gmail.com
}

Received: 18 May 2019, Revised and Accepted: 15 Jul 2019

\begin{abstract}
Objective: Pulmonary fibrosis (PF) is an irreversible and untreatable human disease encompasses a large group of chronic lung disorders associated with excessive remodeling, scarring, and fibrosis.

The current work was designed to study the harmful effects of methotrexate (MTX) administration on the lung and the possible protective role of Carthmus tinctorius leaves extract. The animals were utilized in this study.

Methods: A total of 40 male healthy adult Wistar albino rats with anaverage body weight of $200 \pm 25$ g, were divided into four groups (10 animals each). G1: control group, G2: MTX group, G3: Carthamus tinctorius (CT), group G4:MTX+Carthamus tinctorius(CT). CT was administered orally at a dose of ( $40 \mathrm{mg} / \mathrm{kg} /$ day) for $4 \mathrm{w}$ to G3 and G4. The (CT) group were performed to explore any toxic effect of the (CT) extract on the lung. Rats of G2 and G4 administered $4 \mathrm{mg} / \mathrm{kg}$ dose of MTX orally for $28 \mathrm{~d}$. Rats of G1 were intraperitoneally (i. p) administered with normal saline $0.5 \mathrm{ml} /$ day for four weeks ( $4 \mathrm{wk}$ ) to serveas control. The animals were weighed at the beginning, though, and at the end of experiments.

Results: The study showed that the relative lung weight was significantly increased at (R<0.0 1) in MTX-treated animals in comparison to the control group. A combination of CT extract with MTX revealed significant decrease $(\mathrm{P}<0.01)$ in the lung relative weight in comparison to MTX group. Histopathological examination revealed that lung injury was less severe in group 3 and 4compared to group 2. The results indicated that CT significantly decreased collagen deposition, hydroxyproline content, and ameliorated pathological changes.
\end{abstract}

Conclusion: The study has clearly identified the importance protective role of CT extract on pulmonary fibrosis induced by methoxerate. We recommended CT as one of therapeutic strategy to amelioratethe lung fibrosis associated with methotrexate therapy.

Keywords: Lung, Carthmus tinctorius, Methoxerate, Hydroxyproline, Histopathology

(C) 2019 The Authors. Published by Innovare Academic Sciences Pvt Ltd. This is an open access article under the CC BY license (http://creativecommons.org/licenses/by/4.0/] DOI: http://dx.doi.org/10.22159/ijcpr.2019v11i5.35713

\section{INTRODUCTION}

Fibrosis is a pathophysiological process respond to chronic injury and inflammation that displays as abnormal and excessive deposition of collagen and other extracellular matrix combinations, the accumulation of matrix can disrupt the normal tissue architecture of organ and may lead to its dysfunction [1, 2]. Pulmonary fibrosis (PF) described a group of diseases, which caused interstitial lung damage, ultimately fibrosis, and loss of the lung elasticity. Where Fibrotic lung diseases are heterogeneous groups of chronic lung disorders with progressive marked tissue destruction ending by respiratory failure, that may be produced by a variety of causative agents: infections, toxic materials, immunemediated disorders or might be idiopathic [2]. The estimated incidence of (PF) is 7-16 cases per 100,000 per year and equally distributed in all ethnic groups. It affects men more than women and usually occurs between the ages of 50 to 70. [3]. There are several methods used to induce lung tissue fibrosis in animal models, among these: chemicals (such as bleomycin, methorexae), growth factor gene over expression, irradiation, inorganic particles (such as asbestos, silica and others) [4].

Plants are a valuable source of a wide range of secondary metabolites, which are used as pharmaceuticals, agrochemicals, flavours, fragrances, colours, biopesticides and food additives [5]. Many medicinal plants can atenuae the toxicit of bleomycin, methotrexate, cisplatin, mitomycin- $C$, urethane, cyclophosphamide and many other cyotoxic drugs [6-10]. These plants included: Achillea santolina [11], Alpinia galangal [12], Althaea officinalis [13], Anchusa strigosa [14], Anethum graveolens [15], Astragalus hamosus [16], Bauhinia variegate [17], Brassica rapa [18, 19], Caesalpinia crista [20], Cassia occidentalis [21], Cichorium intybus [22],
Calotropis procera [23], Crocus sativus [24], Ficus cunia [25] and Ficus religiosa [26]. Carthamus tinctorius contained oils, proteins, minerals, phenolics, flavonoids, alkaloids, lignans, carboxylic acids, steroids, polysaccharides, quinochalcone C-glycosides and quinonecontaining chalcones. The previous pharmacological studies showed that the plant possessed central nervous, cardiac, vascular, anticoagulant, reproductive, gastrointestinal, antioxidant, hypolipidemic, metabolic and many other pharmacological effects $[27,28]$. Carthamus tinctorius showed lung protective effects in bleomycin and lipopolysaccharide induced pulmonary injury in mice and rats [29-32]. The current study was desined to investigate the protective effect of Carthamus tinctorius on methotrexate-induced pulmonary fibrosis in rats.

\section{MATERIALS AND METHODS}

\section{Experimental animals}

A total of 40 male 3monthold healthy adult Wistar albino rats with a mean body weight of $200 \pm 25$ g were used in this study. They were bring from the laboratory animal house, College of Science, Thi-Qar University. The animals were inhabited in standard conditions inwell-ventilated polypropylene cages. In controlled room $\left(22 \pm 2 \mathrm{C}{ }^{\circ}\right.$, a 12-hour light/dark cycle), with diet and water ad libitum.

\section{Chemicals and plant extract}

Carthmus tinctorius was bring from the local market of Basrah city/Iraq, diagnosed by the plant herbium of the college of science/Thi-Qar University. The dried leaves were extracted with distilled water and dried in incubator $50{ }^{\circ} \mathrm{C}$. Methotrexate was supplied fromSigma chemicals, and all other chemicals used for this study were of analytical degree. 


\section{Experimental design}

The animals were divided randomly into four groups of 10 rats each. G1: control group (normal saline), G2:MTX group+normal saline, G3:Carthamus tinctorius (CT) group, G4:MTX+CT. CT extract was administered orally at a dose of ( $40 \mathrm{mg} / \mathrm{kg} /$ day) for $4 \mathrm{w}$ to $\mathrm{G} 3$ and G4. The CT group (roup 3) was designed to explore the toxic effect of the CT extract on the lung. Rats of G2 and G4 were administered 4 $\mathrm{mg} / \mathrm{kg}$ of MTX, orally for $28 \mathrm{~d}$. The animals were weighed at the beginning, though, and at the end of experiments. Twenty-four hours after the last doses of the treatments, the rats were lightly anesthetized by chloroform inhalation, killed by neck dislocation, blood samples were drawn by heart puncture, samples were collected in plastic test tubes, centrifuged at $3000 \mathrm{rpm}$ for $20 \mathrm{~min}$, sera were separated and kept in vials to be used for the biochemical investigation. Histological study was carried out by routin histological techniques. Masson'strichrome staining protocol for collagen fibers was performed according to previous study [33].

\section{Biochemical assay}

Hydroxyproline (HP) content in lung tissue was measured spectrophotometrically according to the method described by Woessner [34].

\section{Statistical analysis}

Student t-test was used to determine the significance among the treated group in comparison with positive and negative controls [35].

\section{RESULTS}

Table 1 shows that the lungs relative weight $(\mathrm{mg} / 100 \mathrm{~g}$ body weight) was significantly increased $(\mathrm{P}<0.01)$ in MTX treated group in comparison with control group. CT extract alone did not induced significant changes in the lung relative weight in comparison with control. However, when it was used with MTX, it significantly decreased $(\mathrm{P}<0.01)$ the lung relative weight in comparison to MTX group (table 1).

Table 1: Relative weight of lung $(\mathrm{mg} / 100 \mathrm{~g} \mathrm{bw})$ in methotrexate and Carthmus tinctorius treated rats

\begin{tabular}{lll}
\hline Treated groups & mean \pm SD $(\mathbf{m g} / \mathbf{1 0 0 g b w t})$ & P-value \\
\hline Control & $0.621 \pm 0.064$ & \\
MTX & $0.963 \pm 0.469$ & 0.01 \\
CT & $0.791 \pm 0.315$ & NS \\
MTX+CT & $0.830 \pm 0.178$ & 0.01 \\
\hline
\end{tabular}

MTX significantly elevated hydroxyl-proline (HYP) content $(\mathrm{P}<0.001)$ in comparison with control. While using of plant extract (TC) alone also significantly decreased HYP below control limit
$(\mathrm{P}<0.05)$, when it used in combination with $(\mathrm{MTX})$, it significantly reduced the elevated level of $(\mathrm{HYP})$ content $(\mathrm{P}<0.01)$ in comparison to (MTX) group (table 2).

Table 2: Hydroxyproline (HYP $\mu \mathrm{g} / \mathrm{ml}$ ) concentration in methotrexate and Carthmus tinctorius treated rats

\begin{tabular}{lll}
\hline Treated subgroups & Mean \pm SD $(\mu \mathrm{g} / \mathrm{ml})$ & P-value \\
\hline Control & $1.106 \pm 0.193$ & $<0.001$ \\
MTX & $2.516 \pm 0.114$ & $<0.05$ \\
CT & $1.034 \pm 0.174$ & $<0.01$ \\
CT + MTX & $1.311 \pm 0.217$ & \\
\hline
\end{tabular}

\section{Histopathological assays}

Microscopic investigation of rat lung of control group showed normal architecture, thin alveolar septa, clear alveolar cavities. The lung tissue appeared normal and alveoli were homogeneously distributed (fig. A). The alveolar sacs occurred at the termination of the alveolar ducts. The wall of the terminal bronchiole were devoided of cartilage, each bronchiole lined with folded simple cuboidal epithelial tissue rested on thin basal lamina surrounded by strands of smooth muscle and connective tissue layers (fig. B).

The lung sections of MTX-treated rats showed heavy infiltration with mononuclear inflammatory cells mostly lymphocytes, macrophages, moderate degeneration of bronchioles epithelium with fewer fibroblasts within interalveolar septa. Moreover, interstitial deposition of dense collagen fibers was visualized around blood vessels and in the interalveolar septa, with obvious hypertrophy of the tunica media together with excessive collagen deposition in the adventitia (fig., C and D). Furthermore, some sections showed increased cellularity of alveolar septum which appeared look-like lymphatic nodule, the intra-alveolar fibrosis with collagenous bands accompanying great sepal thickness with diffuse damage to lung architecture (fig. E).

Other sections, showed complete absence of alveoli and the parenchyma tissue replaced by fibrinous exudates network trapped the inflammatory cells, extensive areas of newly blood vessels (angiogenesis) were also noticed (F). On the other hand, staining with Masson's trichrome of lung sections of MTX group, demonstrated heavy deposition of collagen fibrous tissue as marked thickening of the interalveolar septa, together with increased fibrous tissue around the bronchiole $(\mathrm{H})$. The histological sections of lungs of rats intoxicated with MTX and treated with CT extract, showed some collapsed damaged alveoli; but with less collagens in the alveolar spaces than that in methotrexate group. The section showed moderate of fibrosis and slight pulmonary damage. Most of alveoli appeared normal (fig. G).

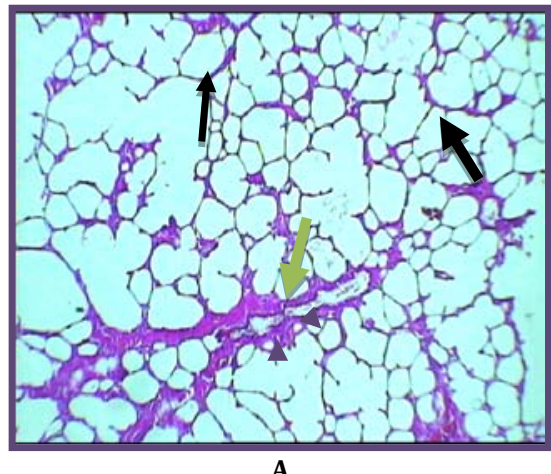

A

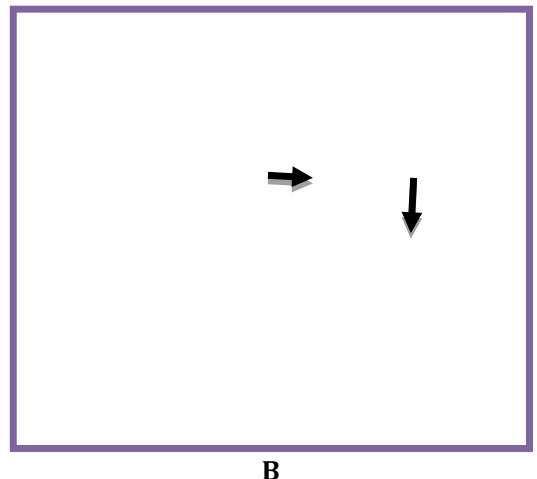




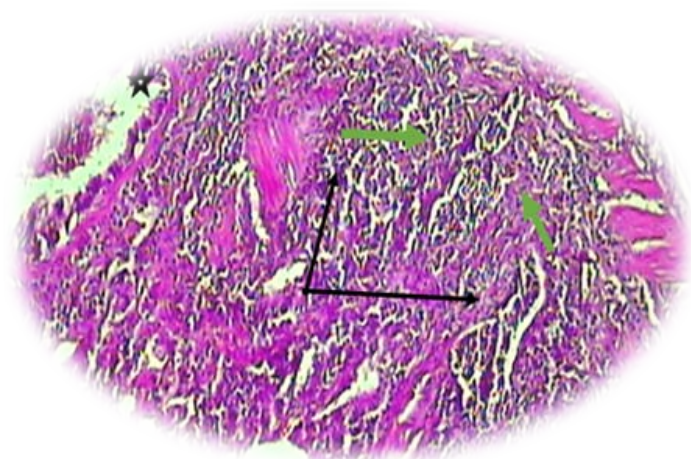

C

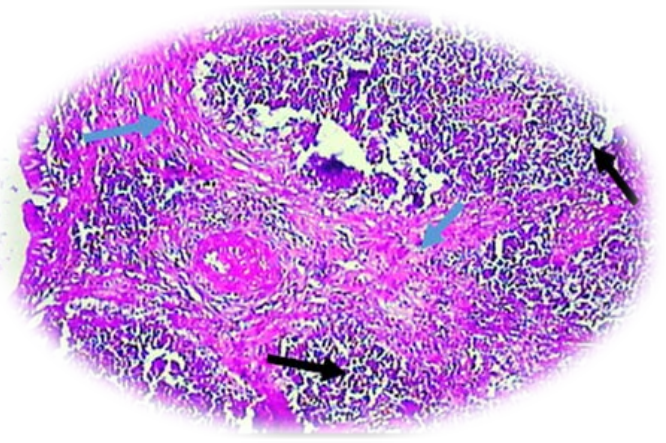

E

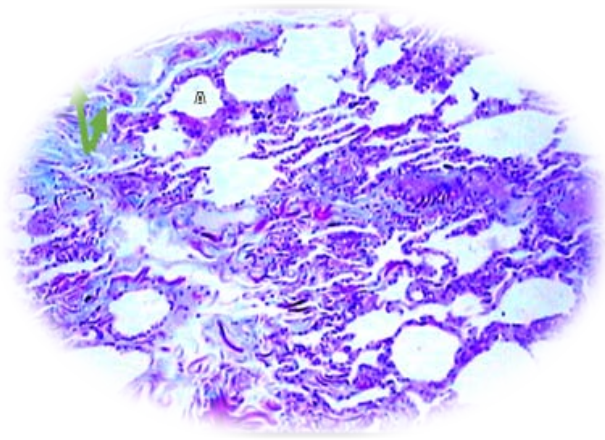

G

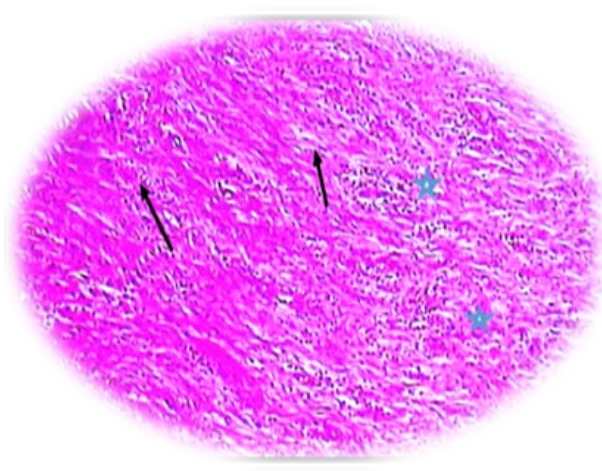

D

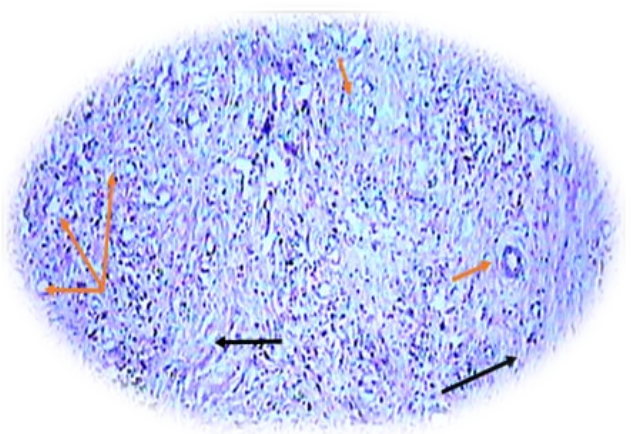

$\mathbf{F}$

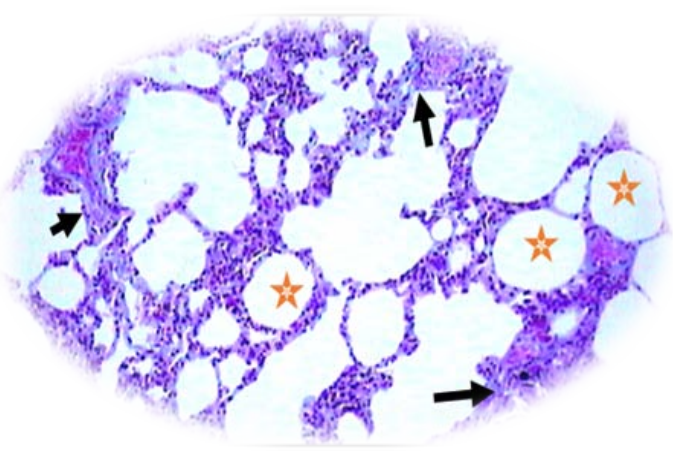

$\mathrm{H}$

Fig. 1: (A,B,C,D,E,F,H,G) effect extract of CT at $40 \mathrm{mg} / \mathrm{kg}$ against MTX-induced pulmonary fibrosis in normal rat lung. Section in normal lung tissue (G1).(A) appear normal structure of alveoli, thinalveolar septa, and loose connective tissue containing capillary network around the alveoli, normal alveolar ducts, branches of terminal bronchiole $(\rightarrow$ ). (B) showing alveoli were homogeneously distributed $(\longrightarrow)$ ).(HandE 40X), (C) Section in rat lung from MTX-induced PF group showed extensive multiple infiltration areas of mononuclear inflammatory cells $(\longrightarrow$ )multifocal areas of fibrosis $(\longrightarrow$ )and inflammatory exudates marked intraterminal bronchiolar lumen( $(*)$ (HandE. 100X), (D) Section of the lung of rat from MTX-induced PF group revealed extensive areas of massive pulmonary fibrosis $(\longrightarrow$ ), with heavy infiltration of inflammatory cells ( $\left.{ }^{(}\right)$. (HandE.100X), (E) Section of the lung from MTX-treated rat, demonstrated an increase in cellularity of alveolar septum look-like lymphatic nodule $(\rightarrow$ )and intra-alveolar fibrosis with collagenous bands accompanying great septal thickness $(\rightarrow$ ).(HandE. 100X), (F) Section in lung from rat treated with MTX drug, showed distortion and complete absent of alveoli and replacement of lung parenchyma by fibrinous exudates network $(\rightarrow$ ) trapped with inflammatory cells,as well as extensive area of newly blood vessels (angiogenesis) ( $\longrightarrow$ ). (HandE. 100X), (G) Section in the lung of rat treated with MTX drug showed marked thickening of interalveolar septa, evident deposition of collagen in the subplueral $(\rightarrow$ ) perivascular space around blood vessels (Masson's trichrome 200X), $(\mathrm{H})$ Photomicrograph of lung section from rat treated with (MTX and CTextract), showedless fibrosis areas with mild inflammation ( $\rightarrow$ ) due to receding collagen deposition, normal alveoli ( ) (Masson's trichrome X100)

\section{DISCUSSION}

Pulmonary fibrosis is advanced fatal lung disorder. It is the end stage of a wide range of lung inflammatory conditions, is amongst the most common interstitial lung diseases impacting over 5 million individuals worldwide with average survival time of about 3years [1]. Despite extensive researches, there are no reports about any medication that can significantly ameliorate pulmonary fibrosis. The only current effective approach is lung transplantation. His study was performed to investigate the possibility of the protective effect of Carthamus tinctorius in methotrexate treatment which associated with lung injury [36-37]. The beneficial effect of Carthamus tinctorius leaves extract in methotrexate-induced pulmonary fibrosis recorded in this study could be attributed toits ability to 
minimize cytotoxic agents-induced increase of mRNA level of tumor necrosis factor (TNF)- $\alpha$, interleukin (IL)- $1 \beta$ and transforming growth factor (TGF)- $\beta 1$ in lung homogenates. Moreover it inhibited the increased activation of nuclear factor $(N F)-\kappa B$ and phosphorylation of p38 mitogen-activated protein kinases (MAPK) in lung tissue [29]. It was studied in rat's pulmonary fibrosis induced by bleomycin (BLM) and on differentiation of lung fibroblast into myofibroblast stimulated by transforming growth factor- $\beta 1$ (TGF$\beta 1)$. It alleviated the increase of hydroxyproline content in the lung tissues and pathologic changes of pulmonary fibrosis caused by BLM instillation. It also prevented the increase of $\alpha$-SMA positive cells and TGF- $\beta 1$ expression induced by BLM. These effects were more significant with the using of high dose. Moreover, italso inhibited the expression of $\alpha$-SMA during differentiation of lung fibroblast into myofibroblast stimulated by TGF- $\beta 1$ [31]. Its administration significantly attenuated inflammatory cell infiltration and alleviated pulmonary edema induced by lipopolysaccharide (LPS) in mice. Moreover, it decreased NF- $\kappa$ B p65 nuclear translocation, inhibited proinflammatory cytokine TNF- $\alpha$, IL- $1 \beta$ and IL- 6 mRNA expression and promoted antiinflammatory cytokine IL-10 gene expression following LPS injection. Pulmonary p38 MAPK phosphorylation was upregulated $4 \mathrm{~h}$ after LPS treatment, which could be suppressed by pretreatment with the extract [30]. Furthermore, its efficacyin acute lung injury (ALI) was studied in rats. It alleviated pulmonary edema, reduce acidosis, keep $\mathrm{PaO}_{2}$ from descending, inhibit inflammatory cell infiltration, inhibit rat lung TNF-alpha and ICAM-1 mRNA expression and plasma IL-6 and IL-1beta level elevation [31]. Accordingly, the lung protective effect of Carthamus tinctorius could be attributed to many mechanisms.

\section{CONCLUSION}

However, additional research is necessary to understand the precise mechanisms by which CT extract help prevent lung damage. Further studied were required to introduce this plant in medical practice as a result of efficacy and safety.

\section{FUNDING}

The author received no fund from any source.

\section{AUTHORS CONTRIBUTIONS}

All authors participated in drafting the and approving the manuscript.

\section{CONFLICT INTERESTS}

The author confirm that this paper's content has no conflict of interests

\section{REFERENCES}

1. Alessandro P, Ronen S, Chrishan S, Samuel RA, Bathgate D, Arie Zauberman, et al. Prevention of bleomycin induced pulmonary fibrosis by a novel antibiotics peptide with relaxin-like activity. J Pharmacol Exp Ther 2010;335:589-99.

2. Kisselcva, Tatiana B, David A. Mechanisms of fibrogenesis. Exp Boil Med 2008;233:109-22.

3. Raghir G, Weycker D, Edelsberg J. Incidence of prevalence of idiopathic pulmonary fibrosis. Am J Respire Crit Care Med 2006;74:810-6.

4. Wynn TA. Common of unique mechanizes regulate fibrosis in various fibro proliferative diseases. J Clin Merest 2007;117:524-9.

5. Al-Snafi AE. Central nervous and endocrine effects of Myristica fragrans. $4^{\text {th }}$ Arabic Conf. of Medicinal plants, Thamar Univ. Yemen; 1999. p. 111-21.

6. Al-Snafi AE. Therapeutic properties of medicinal plants: a review of their detoxification capacity and protective effects (part 1). Asian J Pharm Sci Technol 2015;5:257-70.

7. Al-Snafi AE. Detoxification capacity and protective effects of medicinal plants (part 2): plant based review. IOSR J Pharm 2016;6:63-84.

8. Al-Snafi AE, Thwaini MM. Nephro-protective effects of Arabian medicinal plants (part 1). Res J Pharm Biol Chem Sci 2018;9:1504-11.
9. Al-Snafi AE, Thwaini MM. Arabian medicinal plants with hepatoprotective activity (part 1). Res J Pharm Biol Chem Sci 2018;9:1469-97.

10. Al-Snafi AE. Immunological effects of medicinal plants: a review (part 2). Immun Endoc Metab Agents Med Chem 2016;16:100-21.

11. Al-Snafi AE. Chemical constituents and pharmacological activities of Milfoil (Achillea santolina)-a review. Int J Pharm Tech Res 2013;5:1373-7.

12. Al-Snafi AE. The pharmacological activities of Alpinia galangala review. Int J Pharm Res Scholars 2014;3:607-14.

13. Al-Snafi AE. The Pharmaceutical importance of Althaea officinalis and Althaea rosea: a review. Int J Pharm Tech Res 2013;5:1387-5.

14. Al-Snafi AE. The pharmacology of Anchusa italica and Anchusa strigosa-a review. Int J Pharm Pharm Sci 2014;6:7-10.

15. Al-Snafi AE. The pharmacological importance of Anethum graveolens-a review. Int J Pharm Pharm Sci 2014;6:11-3.

16. Al-Snafi AE. Chemical constituents and pharmacological effects of Astragalus hamosus and Astragalus tribuloides grown in Iraq. Asian J Pharm Sci Tech 2015;5:321-8.

17. Al-Snafi AE. The pharmacological importance of Bauhinia variegata a review. J Pharm Sci Res 2013;4:160-4.

18. Dharani MI, Kalava SV. A study on the protective efficacy of Brassica rapa chinensis against bleomycin induced pulmonary fibrosis. Int J Pharm Pharm Sci 2014;6:53-8.

19. Al-Snafi AE. The pharmacological importance of Brassica nigra and Brassica rapa grown in Iraq. J Pharm Biol 2015;5:240-53.

20. Al-Snafi AE. Pharmacology and medicinal properties of Caesalpinia crista-an overview. Int J Pharm 2015;5:71-83.

21. Al-Snafi AE. The therapeutic importance of Cassia occidentalisan overview. Indian J Pharm Sci Res 2015;5:158-71.

22. Al-Snafi AE. Cardiovascular effects of Carthamus tinctorius: a mini-review. Asian J Pharm Res 2015;5:199-209.

23. Al-Snafi AE. The constituents and pharmacological properties of Calotropis procera-an overview. Int J Pharm Rev Res 2015;5:259-75.

24. Al-Snafi AE. The pharmacology of Crocus sativus-a review. IOSR J Pharm 2016;6:8-38.

25. Al-Snafi AE. Nutritional and pharmacological importance of Ficus carica-a review. IOSR J Pharm 2017;7:33-48.

26. Al-Snafi AE. Pharmacology of Ficus religiosa-a review. IOSR J Pharm 2017; 7:49-60.

27. Al-Snafi AE. The chemical constituents and pharmacological importance of Carthamus tinctorius-an overview. J Pharm Biol 2015;5:143-66.

28. Al-Snafi AE. Cardiovascular effects of Carthamus tinctorius: a mini-review. Asian J Pharm Res 2015;5:199-209.

29. Wu Y, Wang L, Jin M, Zang BX. Hydroxysafflor yellow a alleviates early inflammatory response of bleomycin-induced mice lung injury. Biol Pharm Bull 2012;35:515-22.

30. Sun CY, Pei CQ, Zang BX, Wang L, Jin M. The ability of hydroxysafflor yellow a to attenuate lipopolysaccharideinduced pulmonary inflammatory injury in mice. Phytother Res 2010;24:1788-95.

31. Wang XF, Jin M, Tong J, Wu W, Li JR, Zang BX. Protective effect of hydroxysafflor yellow A against acute lung injury induced by oleic acid and lipopolysaccharide in rats. Yao Xue Xue Bao 2010;45:940-4

32. O'Connor CM, O'Brien A, Sweeny EC, FitzGerald MX. Progress of bleomycin-induced lung fibrosis in rabbits. Br J Exp Path 1986;67:461-71.

33. Luna LG. Manual of histological staining methods of the armed forces institute of pathology. Cornell University; 1968.

34. Woessner JF. The determination of hydroxyproline in tissue and protein samples containing small proportions of this imino acid. Arch Biochem Biophys 1961;93:440-7.

35. Sabin I, Everit S. A Handbook of statistical analyses lesing SPSS, Chapman of Hell CRC, Washington; 2004.

36. Gross TG, Hunninghake GW. Idiopathic pulmonary fibrosis. New Engl J Med 2001;345:517-25.

37. Imokawa S, Colby TV, Leslie KO, Helmers RA. Methotrexate pneumonitis: review of the literature and histopathological findings in nine patients. Eur Respir J 2000;15:373-81. 